\title{
NODULE PREFERENCE BY FIRST INSTAR CLOVER ROOT WEEVIL
}

\author{
D.L. HACKELL and P.J.GERARD \\ AgResearch, Ruakura Research Centre, Private Bag 3123, Hamilton,
New Zealand
}

Corresponding author: deborah.hackell@agresearch.co.nz

\begin{abstract}
Laboratory experiments were undertaken to investigate attraction of first instar clover root weevil (Sitona lepidus) towards different clover nodules. Two choice tests were used to assess larval preference between red and white clover nodules and nitrogen fixing and non-nitrogen fixing white clover nodules. The assays were run over $24 \mathrm{~h}$ in individual Petri dishes. No difference in attraction was found between red and white clover nodules but larvae showed a strong preference towards nitrogen fixing white clover nodules $(\mathrm{P}=0.001)$.
\end{abstract}

Keywords: Sitona lepidus, first instar, attraction, nodules.

\section{INTRODUCTION}

Clover root weevil (CRW) (Sitona lepidus Gyllenhal (Coleoptera: Curculionidae)) was first identified in New Zealand in 1996 (Barratt et al. 1996) and is a major pasture pest throughout its North Island distribution. Feeding by CRW larvae occurs on the roots, stolons and nodules of clovers (Trifolium spp.), with higher larval numbers being found under white clover (T. repens) than red (T. pratense) (Watson et al. 2002). Feeding damage by CRW larvae affects the plant's nutrient uptake and leaves it prone to disease, greatly reducing clover persistence in pasture (Gerard 2001). This is a considerable loss to New Zealand farmers since clover not only supplies livestock with an excellent food source but also has the added benefit of its root nodules being able to fix atmospheric nitrogen.

Early instar larvae of all Sitona species are highly dependent on legume root nodules (Goldson et al. 1988) and although CRW is not an obligate nodule feeder, survival and development of larvae is greatly enhanced in the presence of nodules (Gerard 2001). As in the closely related $S$. discoideus Gyllenhal (Goldson \& French 1983), the time between egg hatch on the soil surface and the discovery of a suitable food source is the most vulnerable time in this pest's life cycle, with typically only $10 \%$ surviving (Eerens \& Hardwick 2003). Understanding how newly hatched CRW locate clover nodules may help explain the differences in larval establishment observed in the field. Most research on CRW behaviour has focused on the adult stage of this pest's life-cycle. This imbalance in CRW research and in fact, for soil dwelling insects in general, is largely due to the difficulty in handling and assessing the earlier life stages. No research on first instar CRW nodule preference prior to this research has been conducted.

This paper reports on two experiments using a simple yet novel technique to determine first instar larval preference towards red (Trifolium pratense) and white clover (T. repens) nodules, and between nitrogen fixing and non-nitrogen fixing nodules.

\section{METHODS}

Nodules were obtained from red (Grasslands Pawera) and white clover (Grasslands Kopu II) plants grown in autoclaved sand. The white clover plants had been grown from sterilised stolon cuttings while the red clover was grown directly from seed. Inoculation of clover plants with nitrogen fixing bacteria, Rhizobia ICC101, occurred 5 days after cuttings were taken or 7 days from germination. A separate tray of white clover cuttings was inoculated at the same time with Rhizobia ICC105 (Elliot 1997), which produces 
nodules on white clover that don't fix atmospheric nitrogen. On the day of CRW egg hatch, plants were destructively sampled and sand was removed from the roots by washing. Under a microscope, nodules were selected and removed at the point of root attachment using a scalpel. These were then placed on damp filter paper in a labelled glass Petri dish and used within $2 \mathrm{~h}$ of detachment.

Adult CRW were collected from clover-dominated paddocks within the property of AgResearch. These were transferred into the mesh-based top of a two-tier cage (Goldson et al. 1992) and fed white clover foliage. Freshly laid eggs were collected from the lower tier, surface sterilised using $10 \%$ formalin, placed in a Petri dish on damp filter paper, and held at $25^{\circ} \mathrm{C}$ until hatch. Larvae were used within $12 \mathrm{~h}$ of egg hatch.

\section{Experiment one}

Thirty $90 \mathrm{~mm}$ diameter Petri dishes containing water agar were used, 20 as treatments and 10 as controls (without nodules). The Petri dishes were divided into equal quarters, and a single excised nodule placed in each quarter. Two similar sized nodules from red clover and two from white clover were positioned randomly and recorded on a template as to which nodule type was in which quarter of the Petri dish. One newly hatched larva was placed using a fine paintbrush in the centre of the Petri dish, which was then sealed using Parafilm ${ }^{\circledR}$. All Petri dishes were placed in a dark controlled environment room at $20^{\circ} \mathrm{C}$ with $90-100 \%$ relative humidity and left for $24 \mathrm{~h}$. After that time, larvae were removed and their final position recorded. Under a microscope, nodules were identified as to whether they had been fed on. Petri dishes were then left for two days by which time bacteria left by the larvae had multiplied sufficiently for larval tracks to be visible on the water agar. Larval tracks were traced onto paper and analysed with a Silva® digital map measurer.

\section{Experiment two}

The same procedure was followed as in Experiment one. However, a choice of two similar sized white clover nodules that were nitrogen fixing and two that were non-nitrogen fixing were provided instead, with one nodule being positioned randomly in each quarter.

\section{Statistical analysis}

Feeding preference data was analysed using both binominal and Chi square analysis. For distances travelled by larvae, a one way ANOVA was conducted.

\section{Experiment one}

\section{RESULTS}

No significant feeding preference $(\mathrm{P}=0.73)$ was shown for either red or white clover nodules. Of larvae that chose to feed, both nodule types were similarly fed on (15\% red and $20 \%$ white, $20 \%$ on both) (Fig. 1). A large proportion of larvae did not feed (45\%) even though larval tracks showed all larvae except one found at least one nodule during the experimental period.
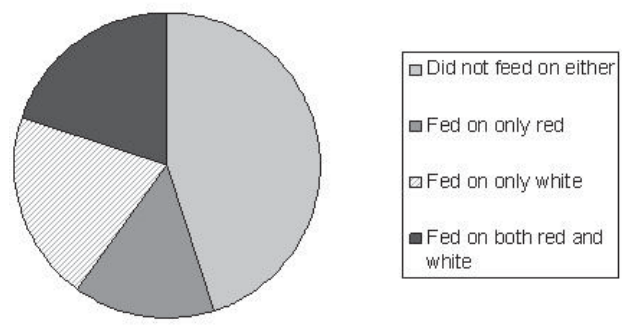
FIGURE 1: Feeding preferences of first instar S. lepidus larvae $(\mathbf{n}=20)$ offered
choice of white or red clover nodules. 
A one way ANOVA found no significant difference $(\mathrm{P}=0.72)$ between distances travelled by larvae in quarters with white clover nodules $(16.2 \mathrm{~cm})$ compared with quarters with red clover nodules $(14.6 \mathrm{~cm})$. Mean distances moved by larvae in Petri dishes containing both red and white clover nodules were similar to that of the controls where no nodules were present ( $29.4 \mathrm{~cm}$ compared with $28.5 \mathrm{~cm}$ respectively).

\section{Experiment two}

Choice tests between nitrogen fixing and non-nitrogen fixing white clover nodules showed a strong preference $(\mathrm{P}=0.001)$ for nitrogen fixing nodules (Fig. 2). Out of 20 replicates, $13(65 \%)$ showed feeding on nitrogen fixing nodules only. Two (10\%) larvae showed feeding on both nitrogen fixing and non-nitrogen fixing nodule types but no larvae fed solely on non-nitrogen fixing nodules. The remaining five replicates showed no feeding.

The average distance moved by larvae within Petri dish quarters containing nitrogen fixing nodules was not significantly different $(\mathrm{P}=0.52)$ from the distance travelled by larvae within quarters containing non-nitrogen fixing nodules. Total distances moved by larvae in Petri dishes containing nitrogen fixing and non-nitrogen fixing nodules $(38 \mathrm{~cm})$ were on average slightly greater than distances travelled by larvae in control Petri dishes where no nodules were present $(28.5 \mathrm{~cm})$. However, these were found not to be statistically significant $(\mathrm{P}=0.35)$.

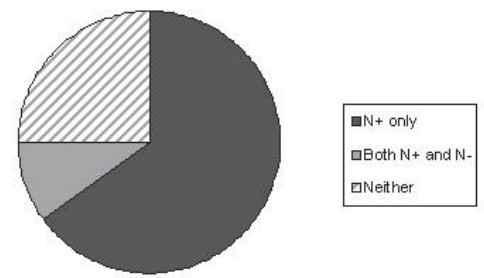

\section{FIGURE 2: Feeding preferences of first instar $S$. lepidus larvae $(\mathbf{n}=20)$ offered choice of nitrogen fixing and non-nitrogen fixing white clover nodules.}

\section{DISCUSSION}

Experiment one demonstrates that first instar CRW larvae have no preferences between red and white clover nodules and will feed on both. In the field, a choice between the clover types may be available and although the adults may show marked feeding preferences (Hardwick 1998; Watson et al. 2002), the results indicate first instar CRW larvae would locate nodules from both clover types. Therefore, the differences in larval populations observed under red and white clovers in the field are likely to be an outcome of adult distribution, rather than larval behaviour. It is likely that the stimuli that enable first instar larvae to locate and feed on both red and white clover nodules are the same.

A marked proportion of larvae did not feed in Experiment one although larval tracks to the nodules were shown for all, but one replicate. This is probably related to the experimental set up. Within a soil structure, nodule odours would permeate air spaces with highest gradients closest to the nodule. Possibly odours emitted by the four equallyattractive excised nodules within a single Petri dish may have flooded the entire air space and overloaded larval senses such that some did not respond appropriately on arrival at the nodule. In addition, some larvae may not have fed as they may have been unsettled by the absence of contact stimuli other than on their ventral surfaces. Contact stimuli would occur in the soil.

Larval movement in treatment Petri dishes compared with control Petri dishes was not significantly different in both experiments. However, data was influenced by two unusually large larval movement responses in the controls of both experiments. If these two replicates were omitted, there was a trend for less movement in the controls than the treatments, suggesting the presence of a stimulus eliciting a movement response. This 
type of general response is common with insects and would assist vulnerable first instar larvae in finding their preferred food source.

The strong preference towards nitrogen fixing nodules over non-nitrogen fixing nodules found in Experiment two suggests that volatiles associated with nitrogen fixation may be the stimuli that attract CRW larvae to nodules. This makes good ecological sense. CRW larvae have greater survival and faster development on nodulated plants than nonnodulated plants (Gerard 2001). Nitrogen fixing root nodules have high concentrations of specific amino acids and it has been speculated by Greenwood \& Bathurst (1978) that the widespread dependence of early Sitona spp. instars on nodules is because these amino acids provide the best food source for rapid development.

Volatiles produced during nitrogen fixation that may elicit a host finding response include asparagine. This volatile amide serves as a protein precursor (Taiz \& Zeiger 1998), and would have excellent nutritional value for growing first instar larvae. Nodules provide a sink for asparagine, which can also be found in the cytosol of roots. Therefore asparagine also could serve as a feeding stimulant for all larval stages.

Results from this study indicate that it is the Rhizobia rather than the plant, that determines first instar CRW nodule preference, and that the attraction is associated with the process of nitrogen-fixation. Further research is required to identify the active compounds that attract first instar CRW larvae and stimulate a feeding response. The identification of these compounds may allow development of new strategies to protect legumes from damage by Sitona species worldwide.

\section{ACKNOWLEDGMENTS}

This work was conducted as part of a masterate study by the senior author, who wishes to acknowledge supervision by Dr Nick Ling, University of Waikato, and Dr Pip Gerard. We acknowledge input from Jim Crush and Prof Warwick Silvester and that of referees Dr Scott Hardwick and Tina Eden. We also acknowledge the New Zealand Plant Protection Society for a research scholarship awarded in 2003.

\section{REFERENCES}

Barratt, B.I.P.; Barker, G.M.; Addison, P.J. 1996: Sitona lepidus Gyllenhal (Coleoptera: Curculionidae), a potential clover pest new to New Zealand. N.Z. Entomol.19: 23-30.

Eerens, J.P.J.; Hardwick, S. 2003: Factors affecting clover root weevil (Sitona lepidus) numbers and clover production. N. Z. J. Agric. Res. 46: 305-310.

Elliot, R. 1997: Interaction of Caucasian clover Rhizobia with white clover. MSc thesis. University of Otago, New Zealand.

Gerard, P.J. 2001: Dependence of Sitona lepidus (Coleoptera: Curculionidae) larvae on abundance of white clover Rhizobium nodules. Bull Entomol. Res. 91: 149-152.

Goldson, S.L.; Frampton, E.R.; Proffitt, J.R. 1988: Population dynamics and larval establishment of Sitona discoideus (Coleoptera: Curculoinidae) in New Zealand lucerne. J. Appl. Ecol. 25: 177-195.

Goldson, S.L.; French, R.A. 1983: Age-related susceptibility of lucerne to Sitona weevil, Sitona discoideus (Coleoptera: Curculoinidae) larvae and associated patterns of adult infestation. N. Z. J. Agric. Res. 26: 251-255.

Goldson, S.L.; McNeill, M.R.; Phillips, C.B.; Proffitt, J.R. 1992: Host specificity testing and suitability of the parasitoid Microctonus hyperodae (Hym.: Braconidae, Euphorinae) as a biological control agent of Listronotus bonariensis (Col.: Curculionidae) in New Zealand. Entomophaga 37: 483-498.

Greenwood, R.M.; Bathurst, N.O. 1978: Effect of Rhizobial strain and host amino acid patterns in legume root nodules. N. Z. J. Sci. 21: 107-120.

Hardwick, S. 1998: laboratory investigations into feeding preferences of adult Sitona lepidus Gyllenhall. Proc. 51 st N.Z. Plant Prot. Conf.: 5-8.

Taiz, L.; Zeiger, E. 1988: Plant Physiology - second edition. Sinauer Associates Incorporated. Massachusetts, United States of America. 792 p.

Watson, R.N.; Eerens, J.P.J.; Davis, L.T. 2002: Clover root weevil feeding and larval numbers on red and white clover seedlines. N.Z. Plant Prot. 55: 252-257. 